\title{
Correspondence:
}

\section{Coexistence of proangiogenic potential and increased MMP-9, TIMP-1, and TIMP-2 levels in the plasma of patients with critical limb ischemia ${ }^{* \#}$}

\author{
Radosław WIECZÓR ${ }^{\dagger 1,2}$, Anna Maria WIECZÓR ${ }^{1}$, \\ Arleta KULWAS ${ }^{1}$, Grzegorz PULKOWSKI ${ }^{2}$, \\ Jacek BUDZYŃSKI ${ }^{2,3}$, Danuta ROŚĆ ${ }^{1}$ \\ ${ }^{\prime}$ Department of Pathophysiology, Faculty of Pharmacy, Nicolaus \\ Copernicus University in Toruń, Ludwik Rydygier Collegium \\ Medicum in Bydgoszcz, Bydgoszcz PL 85-094, Poland \\ ${ }^{2}$ Clinic of Vascular and Internal Medicine, Dr Jan Biziel University \\ Hospital No. 2 in Bydgoszcz, Bydgoszcz PL 85-168, Poland \\ ${ }^{3}$ Department of Vascular and Internal Medicine, Faculty of Health \\ Sciences, Nicolaus Copernicus University in Toruń, Ludwik Rydygier \\ Collegium Medicum in Bydgoszcz, Bydgoszcz PL 85-168, Poland \\ †E-mail: wieczorcmumk@tlen.pl
}

https://doi.org/10.1631/jzus.B1800373

The objective of this study was to assess the angiogenic potential expressed as a quotient of vascular endothelial growth factor A (VEGF-A), as an indicator of proangiogenic activity, and the circulating receptors (soluble VEGF receptor protein R1 (sVEGFR-1) and sVEGFR-2), as indicators of the effect of angiogenic inhibition, depending on the concentrations of matrix metalloproteinase 2 (MMP-2) and MMP-9 and their tissue inhibitor 1 (TIMP-1) and TIMP-2 in the plasma of patients with lower extremity artery disease (LEAD). These blood parameters in patients with intermittent claudication (IC) and critical limb ischemia (CLI) were compared for select clinical and

\footnotetext{
* Project supported by the Nicolaus Copernicus University in Torun, Collegium Medicum in Bydgoszcz, Poland (No. 3/WF-SD)

\# Electronic supplementary materials: The online version of this article (https://doi.org/10.1631/jzus.B1800373) contains supplementary materials, which are available to authorized users

(iD) ORCID: Radosław WIECZÓR, https://orcid.org/0000-0001-80399426

(c) The Author(s) 2019
}

biochemical features. Stimulation of angiogenesis in the plasma of individuals with LEAD was evident as indicated by the significant increase in VEGF-A concentration along with reduced inhibition depending on circulating receptors SVEGFR-1 and sVEGFR-2. Critical ischemia was associated with higher VEGFA, MMP-9, TIMP-1, and TIMP-2 concentrations than in the case of IC.

The 77 patients with LEAD (average age $(63.4 \pm$ 8.8) years) included 62 with IC and 15 with CLI. The exclusion criteria included other severe complications of arterial disease (unstable coronary heart disease, previous myocardial infraction, and/or stroke during the previous year), severe hypertension, chronic obstructive pulmonary disease, and tumor history. The control group consisted of 27 healthy volunteers ( 9 females, 18 males, average age (56 \pm 6 ) years) who were age- and sex-matched with the LEAD group. The patient population characteristics are shown in Table S1. The concentrations of VEGF-A, sVEGFR-1, sVEGFR-2, MMP-2, MMP-9, TIMP-1, and TIMP-2 were measured in plasma obtained from venous blood specimens using an enzyme-linked immunosorbent assay (ELISA; R\&D Systems, USA). The study was approved by the local Bioethics Commission (No. 509/2011) and the clinical research was carried out in accordance with the Helsinki Declaration. Appropriate statistical tests were performed (including the Mann-Whitney $U$ test and the Spearman and/or Pearson correlation coefficient), assuming a value of $P<0.05$ as statistically significant.

Table 1 shows the values of investigated parameters in the test and control groups. Significantly higher levels of VEGF-A, MMP-9, and TIMP-2 and lower levels of sVEGFR-1, sVEGFR-2, MMP-2, and TIMP-1 were observed in the subjects suffering from 
LEAD. The sVEGFR-1/VEGF-A coefficient was $77.7 \%$ lower and the sVEGFR-2/VEGF-A coefficient was nearly $79.5 \%$ lower in patients than in the healthy counterparts. These findings suggested the considerably reduced inhibition of angiogenesis in the patients As well, the concentration of the proangiogenic factor VEGF-A was nearly four times higher in the patients.

Table 2 displays the concentrations of substances analyzed in the subgroups of individuals with IC or CLI and in the control group. The difference in VEGF-A concentrations between the CLI and IC subgroups was statistically significant in favor of patients with CLI $(P=0.02)$. The CLI subgroup revealed a
VEGF-A concentration over six times higher than that of the control group. The VEGF-A level in the IC subgroup was 3.2 times higher than the level in healthy subjects. The sVEGFR-1/VEGF-A and sVEGFR-2/VEGF-A ratios were insignificantly higher in patients with IC compared to the patients with CLI, which suggested that the patients with CLI had the lowest inhibition of angiogenesis and the highest VEGF-A concentration.

In addition, significantly higher levels of MMP-9, TIMP-1, and TIMP-2 were observed in the CLI subgroup compared to the patients with IC ( $P=0.021, P=0.033$, and $P=0.045$, respectively). The

Table 1 Investigated parameters for the test and control groups

\begin{tabular}{cccrcc}
\hline \multicolumn{1}{c}{ Group } & $\begin{array}{c}\text { VEGF-A } \\
(\mathrm{pg} / \mathrm{mL})\end{array}$ & $\begin{array}{c}\text { sVEGFR-1 } \\
(\mathrm{pg} / \mathrm{mL})\end{array}$ & $\begin{array}{c}\text { sVEGFR-2 } \\
(\mathrm{pg} / \mathrm{mL})\end{array}$ & \multicolumn{1}{c}{$\begin{array}{c}\text { sVEGFR-1/ } \\
\text { VEGF-A }\end{array}$} & $\begin{array}{c}\text { sVEGFR-2/ } \\
\text { VEGF-A }\end{array}$ \\
\hline Test $(\mathrm{LEAD}, n=77)$ & $83.90 \pm 66.70$ & $119.44 \pm 42.66$ & $9821.77 \pm 2718.80$ & $2.31 \pm 2.34$ & $193.46 \pm 175.38$ \\
Control $(n=27)$ & $17.60 \pm 7.44$ & $145.86 \pm 62.50$ & $14178.33 \pm 3646.93$ & $10.34 \pm 7.55$ & $946.01 \pm 482.42$ \\
\hline$P$-value & $<\mathbf{0 . 0 0 1}$ & $\mathbf{0 . 0 4}$ & $\mathbf{0 . 0 2}$ & $<\mathbf{0 . 0 0 1}$ & $<\mathbf{0 . 0 0 1}$ \\
\hline \hline Group & MMP-2 $(\mathrm{ng} / \mathrm{mL})$ & $\mathrm{MMP}-9(\mathrm{ng} / \mathrm{mL})$ & $\mathrm{TIMP}-1(\mathrm{ng} / \mathrm{mL})$ & $\mathrm{TIMP}-2(\mathrm{ng} / \mathrm{mL})$ \\
\hline Test $(\mathrm{LEAD}, n=77)$ & $3.03 \pm 2.27$ & $8.60 \pm 7.11$ & $393.88 \pm 342.34$ & $12.69 \pm 5.12$ \\
Control $(n=27)$ & $4.92 \pm 8.25$ & $1.30 \pm 0.90$ & $552.63 \pm 214.27$ & $5.87 \pm 3.80$ \\
\hline \multicolumn{1}{c}{$P$-value } & $\mathbf{0 . 0 3 5}$ & $<\mathbf{0 . 0 0 1}$ & $\mathbf{0 . 0 1 3}$ & $<\mathbf{0 . 0 0 1}$ \\
\hline
\end{tabular}

Data are expressed as mean \pm standard deviation (SD). The difference is considered to be significant at $P<0.05$ (in bold)

Table 2 Parameters in the subgroups of patients with IC and CLI, and in control individuals

\begin{tabular}{|c|c|c|c|c|c|}
\hline Group & $\begin{array}{l}\text { VEGF-A } \\
(\mathrm{pg} / \mathrm{mL})\end{array}$ & $\begin{array}{c}\text { sVEGFR-1 } \\
(\mathrm{pg} / \mathrm{mL})\end{array}$ & $\begin{array}{c}\text { sVEGFR-2 } \\
(\mathrm{pg} / \mathrm{mL})\end{array}$ & sVEGFR-1/VEGF-A & sVEGFR-2/VEGF-A \\
\hline \multicolumn{6}{|c|}{ Test (LEAD, $n=77$ ) } \\
\hline $\mathrm{IC}(n=62)^{\mathrm{a}}$ & $73.10 \pm 47.40$ & $114.75 \pm 43.27$ & $9732.57 \pm 2637.34$ & $2.45 \pm 2.54$ & $208.46 \pm 188.54$ \\
\hline $\operatorname{CLI}(n=15)^{\mathrm{b}}$ & $128.90 \pm 108.27$ & $138.83 \pm 34.92$ & $10190.43 \pm 3104.85$ & $1.74 \pm 1.11$ & $131.44 \pm 83.48$ \\
\hline Control $(n=27)^{\mathrm{c}}$ & $17.60 \pm 7.44$ & $145.86 \pm 62.50$ & $14178.33 \pm 3646.93$ & $10.34 \pm 7.55$ & $946.01 \pm 482.42$ \\
\hline \multicolumn{6}{|l|}{$P$-value } \\
\hline a vs. b & 0.02 & NS & NS & NS & NS \\
\hline a vs. c & $<0.001$ & 0.03 & NS & $<0.001$ & $<0.001$ \\
\hline b vs. c & $<0.001$ & NS & NS & $<0.001$ & $<0.001$ \\
\hline Group & $\begin{array}{l}\text { MMP-2 } \\
\text { (ng/mL) }\end{array}$ & $\begin{array}{l}\text { MMP-9 } \\
\text { (ng/mL) }\end{array}$ & $\begin{array}{l}\text { TIMP-1 } \\
\text { (ng/mL) }\end{array}$ & $\begin{array}{l}\text { TIMP-2 } \\
(\mathrm{ng} / \mathrm{mL})\end{array}$ & \\
\hline \multicolumn{6}{|c|}{ Test (LEAD, $n=77$ ) } \\
\hline $\operatorname{IC}(n=62)^{\mathrm{a}}$ & $3.10 \pm 2.21$ & $7.79 \pm 6.28$ & $358.55 \pm 239.95$ & $12.20 \pm 5.22$ & \\
\hline CLI $(n=15)^{\mathrm{b}}$ & $2.76 \pm 2.56$ & $11.92 \pm 9.38$ & $539.93 \pm 597.46$ & $14.71 \pm 4.31$ & \\
\hline Control $(n=27)^{\mathrm{c}}$ & $4.92 \pm 8.25$ & $1.30 \pm 0.90$ & $552.63 \pm 214.27$ & $5.87 \pm 3.80$ & \\
\hline \multicolumn{6}{|l|}{$P$-value } \\
\hline a vs. b & NS & 0.021 & 0.033 & 0.045 & \\
\hline a vs. c & NS $(0.054)$ & $<0.001$ & $<0.001$ & $<0.001$ & \\
\hline b vs. c & NS & $<0.001$ & NS & $<0.001$ & \\
\hline
\end{tabular}

Data are expressed as mean \pm standard deviation (SD). The difference is considered to be significant at $P<0.05$ (in bold). NS: not significant 
aforementioned parameters were significantly higher in both subgroups than in healthy subjects.

The correlations regarding the concentrations of the MMP-2, MMP-9, TIMP-1, and TIMP-2 were analyzed depending on age, body mass index (BMI), absolute claudication distance, ankle-brachial index (ABI), number of pack-years (Table 3), and the levels of VEGF-A, sVEGFR-1, and sVEGFR-2 (Table 4).

Table 3 Correlation analysis 1

\begin{tabular}{|c|c|c|c|c|}
\hline Parameter & MMP-2 & MMP-9 & TIMP-1 & TIMP-2 \\
\hline Age & NS & NS & NS & NS \\
\hline $\begin{array}{l}\text { Number of } \\
\text { pack-years }\end{array}$ & NS & NS & $\begin{array}{l}R=-0.26 \\
P=0.02\end{array}$ & NS \\
\hline IC distance & NS & $\begin{array}{l}R=-0.27 \\
P=0.02\end{array}$ & NS & NS \\
\hline $\mathrm{ABI}$ & NS & NS & NS & NS \\
\hline BMI & NS & NS & NS & NS \\
\hline
\end{tabular}

IC: intermittent claudication; $\mathrm{ABI}$ : ankle-brachial index; BMI: body mass index; NS: not significant

Table 4 Correlation analysis 2

\begin{tabular}{|c|c|c|c|c|}
\hline Parameter & MMP-2 & MMP-9 & TIMP-1 & TIMP-2 \\
\hline \multirow{2}{*}{ MMP-2 } & & $R=0.26$ & $R=-0.25$ & NS \\
\hline & & $P=0.02$ & $P=0.02$ & \\
\hline \multirow[t]{2}{*}{ MMP-9 } & $R=0.26$ & & NS & NS \\
\hline & $P=0.02$ & & & \\
\hline \multirow[t]{2}{*}{ TIMP-1 } & $R=-0.25$ & NS & & NS \\
\hline & $P=0.02$ & & & \\
\hline TIMP-2 & NS & NS & NS & \\
\hline VEGF-A & NS & NS & NS & NS \\
\hline \multirow[t]{2}{*}{ sVEGFR-1 } & $R=0.23$ & NS & $R=-0.24$ & NS \\
\hline & $P=0.04$ & & $P=0.037$ & \\
\hline sVEGFR-2 & NS & NS & NS & NS \\
\hline
\end{tabular}

NS: not significant

A negative correlation was identified between MMP-9 concentrations and the absolute claudication distance $(R=-0.27 ; P=0.02)$, and the number of packyears and TIMP-1 $(R=-0.26 ; P=0.02)$.

In addition, a positive relationship was observed between the levels of MMP-2 and MMP-9 $(R=0.26$; $P=0.02)$ and sVEGFR-1 $(R=0.23 ; P=0.04)$. Negative correlations were evident between MMP-2 and TIMP-1 $(R=-0.25 ; P=0.02)$ and between TIMP-1 and SVEGFR-1 $(R=-0.24 ; P=0.037)$.

This study focused on identifying the relationships between angiogenesis factors (VEGF-A, sVEGFR-1, sVEGFR-2) and MMPs (MMP-2 and MMP-9), and their inhibitors (TIMP-1 and TIMP-2), based on the evaluation of their concentrations in patients with IC and CLI. This objective was hard to meet due to the presence of many other factors involved in angiogenesis and arteriosclerosis (Rundhaug, 2005; Bogaczewicz et al., 2006; Liu et al., 2006).

VEGF-A is a recognized and undisputed promoter of the multi-stage process of angiogenesis (Jazwa et al., 2016). Soluble receptors types 1 and 2 inhibit the activity of VEGF-A by bonding the factor, which circulates as a biologically inactive complex and significantly reduces VEGF-A availability to the stationary receptor VEGFR2 on the endothelial cell surface. The association of VEGF-A and VEGFR2 is necessary for VEGF-A activation.

The plasma VEGF-A concentration was nearly four-times higher in patients with LEAD than in their healthy counterparts. This difference differentiated patients with CLI from those with IC based on the statistically significantly higher concentrations in the CLI group. The findings are consistent with published results (Findley et al., 2008; Stehr et al., 2010).

Furthermore, our findings indicated the coexistence of elevated levels of serum VEGF-A in patients with CLI and statistically significantly higher levels of MMP-9, TIMP-1, and TIMP-2.

Elevated concentrations of MMP-9 and MMP-2 in patients with LEAD were significantly higher than the levels in the healthy subjects. Similar results were observed by Signorelli et al. (2016). Similarly, as in our studies, when comparing patients with IC $(n=36)$ and CLI ( $n=43)$, Tayebjee et al. (2005) recorded significantly higher levels of MMP-9 (including TIMP-1) in patients with CLI compared to those with IC. Furthermore, higher MMP-9 expression (complementary DNA) was noted in patients with CLI compared with their healthy counterparts. Expression of MMP-2 was reduced and no differences were found within TIMP-1 or TIMP-2 expression (Baum et al., 2007). Of note, the present data revealed a negative correlation between the MMP-9 concentration and the absolute claudication distance, which suggests that higher MMP-9 levels correspond with shorter painless distances.

Among the MMPs, MMP-9 is most strongly related to instability and atherosclerotic plaque rupture (Hobeika et al., 2008). A mouse model was used to prove that the elevated level of MMP-9 leads to increased plaque hemorrhage and plaque rupture. In humans, however, higher serum MMP-9 concentrations 
were observed in patients with unstable coronary heart disease. These concentrations correlated with clinical signs of instability and plaque rupture in coronary and cerebral vessels. The serum concentrations of MMP-2 and MMP-9 were higher in patients with hypertensive than in the control group (Rajzer et al., 2017). Likewise, the values of plasma MMP-9 were higher in patients with type 2 diabetes mellitus (Vitlianova et al., 2015).

With regard to the physiological circumstances, the level of MMPs is adjusted by inhibition that depends on TIMPs and by $\alpha$-2-macroglobuline (a plasma proteinase inhibitor with broad inhibitory specificity). The inhibition of the activity of TIMPs relies on the irreversible bonding with the catalytic domain of MMPs. TIMPs inhibit the activity of MMPs and promote proliferation. The presence of TIMP-1 was determined in fibroblast nucleons and it was demonstrated that TIMP-2 can inhibit endothelial proliferation induced by basic fibroblast growth factor (Lipka and Boratyński, 2008). TIMP-1 and TIMP-2 have antiapoptotic properties (Hrabec et al., 2007; Groblewska et al., 2011; Fink and Boratyński, 2012).

Adjustment processes are disrupted in tissues exposed to ischemia and hypoxia. The coexistence of reduced TIMP levels and an increased activity of MMPs has been frequently observed in pathological circumstances (Kugler, 1999; Herman et al., 2001). Presently, elevated levels of TIMP-1 and decreased levels of TIMP-2 were evident in the patients with LEAD compared to their healthy counterparts. The CLI subgroup of patients displayed high MMP-9 concentration and significantly elevated TIMP-1 and TIMP-2 levels in comparison with the IC subgroup. Changes in the proportion of MMPs-TIMPs and their significance in the development of severe complications of LEAD, such as myocardial infarction and reperfusion, have been investigated (Lalu et al., 2005). Patients with acute myocardial infarction and unstable angina pectoris displayed higher MMP-2 levels compared with patients with stable angina and healthy control subjects (Wu et al., 2016). Presently, complications of severe arterial disease were an exclusion criterion.

The role of MMPs in the breakdown of extracellular matrix proteins and, more importantly, MMPs, by the degradation of the extracellular matrix, can release different substances including growth factors. MMP substrates can be also found on the surface of many types of cells.

A positive activation-modification loop has been observed between MMPs, growth factors, and cytokines (Chase and Newby, 2003). However, presently no significant correlations were apparent between the key proangiogenic factor (VEGF-A) and MMP-2 and/or MMP-9 concentrations, although the concentrations of VEGF-A and MMP-9 were significantly higher in patients with more advanced artery disease, i.e. in the CLI subgroup. When digesting the components of the extracellular matrix, MMPs reveal a range of proangiogenic and anti-angiogenic factors (Zawierucha et al., 2012). This may be evident as the positive correlation between MMP-2 and sVEGFR-1 concentrations that we observed.

The correlations between MMP-2, MMP-9, and angiogenesis parameters in patients with CLI are difficult to clearly explain, since MMPs participate in the development of artery disease, especially in the progression of the atherosclerotic plaque and a compensation response to ischemia and hypoxia that includes angio- and arteriogenesis (Hobeika et al., 2008; Busti et al., 2010). This can be reflected in high gene expression at the mRNA level that has been observed for MMPs (MMP-9) and VEGF-A in subjects with CLI using popliteal artery samples collected during amputation (Baczynska et al., 2016).

The importance of identifying other MMPs (e.g. MMP-1 and MMP-8) has been emphasized in the stratification of patients with CLI concerning their amputation risk when surgical revascularization is done (de Caridi et al., 2016). Since arterial disease is an important concern globally, pathogenetic events that occur in ischemic tissues and the body's compensatory response to ischemia are areas that warrant study.

A limitation of this study is the relatively small sample size of patients with CLI and different numbers of patients with IC and CLI. Examinations of a larger group of patients are underway. The present findings should be considered preliminary.

The activation of angiogenesis that was dependent on significant proangiogenic activity of VEGF-A and reduced inhibition of angiogenesis by receptors sVEGFR-1 and sVEGFR-2 (which are natural angiogenic inhibitors) was observed in patients with 
LEAD. The proangiogenic activity of VEGF-A was significantly higher in the subjects with CLI than in patients with chronic ischemia. In subjects with CLI, high concentrations of VEGF-A were accompanied by elevated levels of MMP-9, TIMP-1, and TIMP-2, which confirms the interaction of proangiogenic factors and MMPs.

\section{Contributors}

Radosław WIECZÓR and Danuta ROŚĆ performed the experimental research and data analysis, wrote and edited the manuscript. Anna Maria WIECZÓR performed the data analysis and wrote the paper. Arleta KULWAS collected and analyzed the data. Danuta ROŚĆ, Grzegorz PULKOWSKI, and Jacek BUDZYŃSKI contributed to the study design. All authors read and approved the final manuscript and, therefore, had full access to all the data in the study and take responsibility for the integrity and security of the data.

\section{Compliance with ethics guidelines}

Radosław WIECZÓR, Anna Maria WIECZÓR, Arleta KULWAS, Grzegorz PULKOWSKI, Jacek BUDZYŃSKI, and Danuta ROŚĆ declare that they have no conflict of interest.

All procedures followed were in accordance with the ethical standards of the responsible committee on human experimentation (institutional and national) and with the Helsinki Declaration of 1975, as revised in 2008. Informed consent was obtained from all patients for being included in the study. Additional informed consent was obtained from all patients for whom identifying information is included in this article.

\section{Open Access}

This article is distributed under the terms of the Creative Commons Attribution 4.0 International License (http://creativecommons.org/licenses/by/4.0/), which permits use, duplication, adaptation, distribution and reproduction in any medium or format, as long as you give appropriate credit to the original author(s) and the source, provide a link to the Creative Commons license and indicate if changes were made.

\section{References}

Baczynska D, Michalowska D, Barc P, et al., 2016. The expression profile of angiogenic genes in critical limb ischemia popliteal arteries. J Physiol Pharmacol, 67(3): 353-362.

Baum O, Ganster M, Baumgartner I, et al., 2007. Basement membrane remodeling in skeletal muscles of patients with limb ischemia involves regulation of matrix metalloproteinases and tissue inhibitor of matrix metalloproteinases. J Vasc Res, 44(3):202-213. https://doi.org/10.1159/000100376

Bogaczewicz J, Dudek W, Zubilewicz T, et al., 2006. The role of matrix metalloproteinases and their tissue inhibitors in angiogenesis. Pol Mer Lek, 21(121):80-85 (in Polish).

Busti C, Falcinelli E, Momi S, et al., 2010. Matrix metalloproteinases and peripheral arterial disease. Int Emerg Med, 5(1):13-25. https://doi.org/10.1007/s11739-009-0283-y

Chase AJ, Newby AC, 2003. Regulation of matrix metalloproteinase (matrixin) genes in blood vessels: a multi-step recruitment model for pathological remodelling. J Vasc Res, 40(4):329-343. https://doi.org/10.1159/000072697

de Caridi G, Massara M, Spinelli F, et al., 2016. Matrix metalloproteinases and risk stratification in patients undergoing surgical revascularisation for critical limb ischaemia. Int Wound J, 13(4):493-499. https://doi.org/10.1111/iwj.12464

Findley CM, Mitchell RG, Duscha BD, et al., 2008. Plasma levels of soluble Tie2 and vascular endothelial growth factor distinguish critical limb ischemia from intermittent claudication in patients with peripheral arterial disease. $J$ Am Coll Cardiol, 52(5):387-393. https://doi.org/10.1016/j.jacc.2008.02.045

Fink K, Boratyński J, 2012. The role of metalloproteinases in modification of extracellular matrix in invasive tumor growth, metastasis and angiogenesis. Post Hig Med Dosw, 66:609-628. https://doi.org/10.5604/17322693.1009705

Groblewska M, Tycińska A, Mroczko B, et al., 2011. The role of matrix metalloproteinases in cardiovascular diseases. Pol Merk Lek, 30(178):235-240 (in Polish).

Herman MP, Sukhova GK, Kisiel W, et al., 2001. Tissue factor pathway inhibitor-2 is a novel inhibitor of matrix metalloproteinases with implications for atherosclerosis. J Clin Invest, 107(9):1117-1126. https://doi.org/10.1172/jci10403

Hobeika MJ, Edlin RS, Muhs BE, et al., 2008. Matrix metalloproteinases in critical limb ischemia. J Surg Res, 149(1): 148-154. https://doi.org/10.1016/j.jss.2007.08.004

Hrabec E, Naduk J, Strek M, et al., 2007. Type IV collagenases (MMP-2 and MMP-9) and their substrates-intracellular proteins, hormones, cytokines, chemokines and their receptors. Post Biochem, 53(1):37-45 (in Polish).

Jazwa A, Florczyk U, Grochot-Przeczek A, et al., 2016. Limb ischemia and vessel regeneration: is there a role for VEGF? Vascul Pharmacol, 86:18-30. https://doi.org/10.1016/j.vph.2016.09.003

Kugler A, 1999. Matrix metalloproteinases and their inhibitors. Anticancer Res, 19(2C):1589-1592.

Lalu MM, Pasini E, Schulze CJ, et al., 2005. Ischaemiareperfusion injury activates matrix metalloproteinases in the human heart. Eur Heart J, 26(1):27-35. https://doi.org/10.1093/eurheartj/ehi007

Lipka D, Boratyński J, 2008. Metalloproteinases. Structure and function. Post Hig Med Dosw, 62:328-336 (in Polish).

Liu P, Sun M, Sader S, 2006. Matrix metalloproteinases in cardiovascular disease. Can J Cardiol, 22(Suppl B):25B30B. 
https://doi.org/10.1016/s0828-282x(06)70983-7

Rajzer M, Wojciechowska W, Kameczura T, et al., 2017. The effect of antihypertensive treatment on arterial stiffness and serum concentration of selected matrix metalloproteinases. Arch Med Sci, 13(4):760-770.

https://doi.org/10.5114/aoms.2016.58825

Rundhaug JE, 2005. Matrix metalloproteinases and angiogenesis. J Cell Mol Med, 9(2):267-285. https://doi.org/10.1111/j.1582-4934.2005.tb00355.x

Signorelli SS, Anzaldi M, Libra M, et al., 2016. Plasma levels of inflammatory biomarkers in peripheral arterial disease: results of a cohort study. Angiology, 67(9):870-874. https://doi.org/10.1177/0003319716633339

Stehr A, Töpel I, Müller S, et al., 2010. VEGF: a surrogate marker for peripheral vascular disease. Eur J Vasc Endovasc Surg, 39(3):330-332.

https://doi.org/10.1016/j.ejvs.2009.09.025

Tayebjee MH, Tan KT, MacFadyen RJ, et al., 2005. Abnormal circulating levels of metalloprotease 9 and its tissue inhibitor 1 in angiographically proven peripheral arterial disease: relationship to disease severity. $J$ Intern $\mathrm{Med}$, 257(1):110-116. https://doi.org/10.1111/j.1365-2796.2004.01431.x

Vitlianova K, Georgieva J, Milanova M, et al., 2015. Blood pressure control predicts plasma matrix metalloproteinase-9 in diabetes mellitus type II. Arch Med Sci, 11(1):85-91. https://doi.org/10.5114/aoms.2015.49208

Wu HY, Shou XL, Liang L, et al., 2016. Correlation between plasma angiopoietin-1, angiopoietin-2 and matrix metalloproteinase-2 in coronary heart disease. Arch Med Sci, 12(6):1214-1219. https://doi.org/10.5114/aoms.2016.62909

Zawierucha P, Kempisty B, Sosińska P, et al., 2012. Molecular aspects of angiogenesis and its role in atherosclerosis. Post Biol Kom, 39(4):589-610 (in Polish).

\section{List of electronic supplementary materials}

Table S1 Characteristics of the study group

\section{中文概要}

题 目: 严重肢体缺血患者血浆中促血管生成潜力与血浆 MMP-9、TIMP-1 和 TIMP-2 水平升高的相关性 研究

概 要: 本研究通过比较间歇性跛行 (IC) 和严重肢体缺 血（CLI）患者的血液参数, 选择合适的临床和 生化特指标, 以评估促血管生成的潜力和抑制血 管生成的作用。结果表明, 通过刺激下肢动脉疾 病（LEAD）病人血浆中的血管生成, 内皮生长 因子 A（VEGF-A）浓度会显著增加, 同时依赖 于循环受体 sVEGFR-1 和 sVEGFR-2 的抑制也会 显著减少。与 IC 病人相比, CLI 病人具有较高的 VEGF-A、金属蛋白酶 9（MMP-9）、金属蛋白 酶组织抑制因子 1（TIMP-1）和 TIMP-2 浓度。

关键词: 严重肢体缺血; 间歇性跛行; 血管内皮生长因子; 金属蛋白酶 